\title{
Time-dependent behaviour of high performance concrete: influence of coarse aggregate characteristics
}

\author{
A. Makani ${ }^{1, a}$, T. Vidal ${ }^{1}$, G. Pons ${ }^{1}$, and G. Escadeillas ${ }^{1}$ \\ ${ }^{1}$ Université de Toulouse, UPS, INSA, LMDC (Laboratoire Matériaux et Durabilité des \\ Constructions), 135, Avenue de Rangueil, F-31 077 TOULOUSE Cedex 4, France
}

\begin{abstract}
This paper examines the influence of coarse aggregate characteristics on the time-dependent deformations of High Performances Concretes (HPC). Four concretes made using the same cement paste but incorporating different types of aggregate (rolled siliceous gravel, crushed granite, crushed limestone and crushed siliceous gravels) were studied in order to investigate the effect of aggregate properties on the compressive strength, modulus of elasticity, shrinkage and creep. The results indicate that the aggregate type has a significant effect on creep and shrinkage deformations of HPC. An influence of the shape of aggregate on time-dependent deformations has also been observed. On the basis of these results, long-term behaviour seems to be correlated to the characteristics of the Interfacial Transition Zone (ITZ) strongly depending on the mineralogical nature and properties of aggregates. The experimental results are compared with the values calculated using the current Eurocode 2 model in order to assess the accuracy of the predictions.
\end{abstract}

\section{Introduction}

Since the last century, concrete has become one of the most used construction materials. Many researches have tried to assess the behaviour of concrete during the service life. The prediction of long-term time-dependent deformations, free shrinkage and creep deformations under sustained load has a great importance in civil engineering design since they affect deflection, loss of pre-stressing force in cables and normal stress distribution in statically indeterminate structures. However, the influence of some parameters on the long term mechanical behaviour still remains not known totally. The importance of the mineralogical characteristics of coarse aggregate on the properties of concrete was pointed out by Baalbaki et al. [1] and Cubaynes and Pons [2]. It is known that the shape and texture of aggregates affect the elastic modulus of concrete. For example, a concrete with ellipsoidal aggregates has a greater elastic modulus than that of spherical aggregates for a given aggregate volume fraction [3]. Alexander [4] asserted that the influence of aggregate type on creep and shrinkage of concrete is due to two effects: water demand of the coarse aggregate and the stiffness of the aggregate restraining movement of the concrete paste. Shrinkage testing by Mokhtarzadeh and French [5] showed that greater shrinkage strains were observed for the mixes made with smooth river gravel as opposed to those made with crushed aggregates. According to numerous researchers,

\footnotetext{
a e-mail : amakani@insa-toulouse.fr
}

This is an Open Access article distributed under the terms of the Creative Commons Attribution-Noncommercial License 3.0, which permits unrestricted use, distribution, and reproduction in any noncommercial medium, provided the original work is properly cited. 
the influence of type of aggregates (e.g. chemical nature, shape and surface conditions) is linked to their effect on the properties of the ITZ [6,7].

In this paper, the results of experiments performed in order to investigate the influence of aggregate type on the instantaneous (modulus of elasticity) and long term (shrinkage and creep) mechanical behaviour of four High Performances Concretes (HPC) are presented. The results are compared with the predictions of the European Code to design concrete structures Eurocode 2 [8] which do not directly take into account this parameter.

\section{Materials and experimental program}

\subsection{Materials and coarse aggregate characteristics}

A CEM I 52.5 R cement was used for all concrete compositions. A condensed silica fume (CSF), rich in $\mathrm{SiO} 2$ (class A) and ultrafine (specific surface area BET of $23 \mathrm{~m}^{2} / \mathrm{g}$ ) was also used. A vinyl acrylic copolymer based super-plasticizer was used to improve the fresh properties of the concrete mix. Natural siliceous river sand (NS) was used as fine aggregates. It has the same origin that the siliceous gravel of this study. The types of aggregates are rolled river siliceous gravel (RS), crushed siliceous gravel (SC), crushed granite (GC) and crushed limestone (LC). They were selected to have contrasting chemical interaction with the cement paste.

Figure 1 shows the aggregate size distribution of the five aggregate types. These curves are determined according to French Standard [9]. The chemical compositions of the rocks are given in Table 1 in terms of major oxides as determined by X-Ray Fluorescence (XRF).
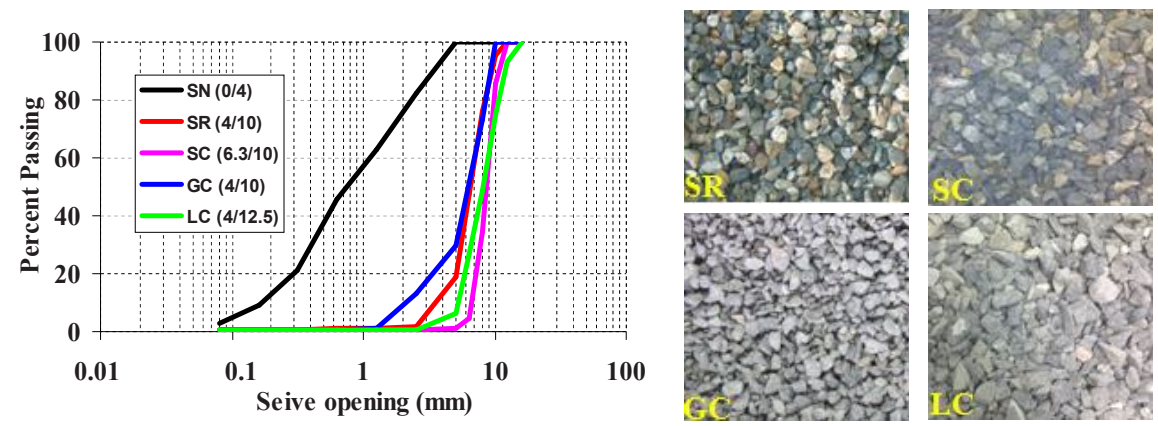

Fig. 1. Aggregate size distribution and photographs of the aggregates.

Table 1. Chemical composition of aggregates obtained using XRF.

\begin{tabular}{|c|c|c|c|c|c|c|c|c|c|}
\hline Constituent & $\mathrm{SiO}_{2}$ & $\mathrm{Al}_{2} \mathrm{O}_{3}$ & $\mathrm{Fe}_{2} \mathrm{O}_{3}$ & $\mathrm{CaO}$ & $\mathrm{MgO}$ & $\mathrm{K}_{2} \mathrm{O}$ & $\mathrm{SO}_{3}$ & $\mathrm{Na}_{2} \mathrm{O}$ & $\begin{array}{c}\mathrm{LOI} \\
\left(800^{\circ} \mathrm{C}\right)\end{array}$ \\
\hline $\mathrm{SN}-\mathrm{SR}-\mathrm{SC}$ & 68.63 & 14.13 & 4.68 & 3.48 & 1.77 & 3.02 & 0.03 & 2.23 & 1.64 \\
\hline $\mathrm{GC}$ & 61.11 & 14.36 & 5.48 & 1.83 & 2.00 & 5.89 & 0.02 & 3.92 & 2.24 \\
\hline $\mathrm{LC}$ & 0.69 & 0.38 & 0.36 & 52.99 & 1.25 & 0.25 & 0.01 & 0.07 & 42.28 \\
\hline
\end{tabular}

Mineralogical analysis of the rocks used was carried out using X-Ray Diffraction (XRD). The siliceous aggregate samples were dark greenish-grey in colour, fine- to medium-grained with a crystalline texture. Its mineralogy consists of quartz with minor quantities of microcline feldspath. The granite aggregate samples were dim gray, fine-grained with a crystalline texture. The mineralogy comprised predominantly of quartz, albite and biotite, with minor quantities of mica. The limestone aggregate samples were light gray in colour, finegrained with a crystalline texture. It contained a few cracks and was filled with recrystallised material. The mineralogy of this aggregate consists of calcite and minor quantities of quartz. 
The mechanical and physical properties of the coarse aggregates selected for this study are presented in Table 2. These properties were determined according to European and French standards. Laboratory tests were carried out in core specimens extracted from each rock type as well as in coarse aggregates obtained directly from industrial production.

The physical properties are rather similar. Only the porosities of the crushed limestone and the crushed siliceous seem higher. The mechanical characteristics are different. The modulus of elasticity and the compressive strength of the crushed limestone are significantly more important than the other materials. However, as rocks specimens were not available for all the materials, it was not possible to perform mechanical tests for all the aggregates. Some results are then extracted from the literature.

Table 2. Mechanical and physical characteristics of used aggregates.

\begin{tabular}{|c|c|c|c|c|c|}
\hline & $\begin{array}{c}\text { Natural } \\
\text { Sand } \\
\text { (SN) }\end{array}$ & $\begin{array}{c}\text { Rolled } \\
\text { Siliceous } \\
\text { (SR) }\end{array}$ & $\begin{array}{c}\text { Crushed } \\
\text { Siliceous } \\
\text { (SC) }\end{array}$ & $\begin{array}{c}\text { Crushed } \\
\text { Granite } \\
\text { (GC) }\end{array}$ & $\begin{array}{c}\text { Crushed } \\
\text { Limestone } \\
\text { (LC) }\end{array}$ \\
\hline Shape & \multicolumn{2}{|c|}{ Rounded } & Angular & Angular & Angular \\
\hline Surface texture & \multicolumn{2}{|c|}{ Smooth } & Crystalline & Crystalline & Crystalline \\
\hline Compressive strength (MPa) & \multicolumn{3}{|c|}{$107^{*}$} & - & $224^{\#}$ \\
\hline Modulus of elasticity $(\mathrm{GPa})$ & \multicolumn{3}{|c|}{$40^{*}$} & $70^{*}$ & $80^{\#}$ \\
\hline Relative density & 2.75 & 2.68 & 2.65 & 2.63 & 2.60 \\
\hline Absorption (\%) & 1.70 & 1.19 & 1.09 & 0.87 & 1.26 \\
\hline Porosity (\%) & 2.52 & 0.43 & 3.81 & 1.65 & 4.62 \\
\hline
\end{tabular}

Values extracted from reference [1,2,4].

\#Average modulus of elasticity of cylindrical drilled rock specimen $(50 \times 100 \mathrm{~mm})$.

\subsection{Experimental Program}

The concrete mixtures were designed with a W/C ratio of 0.35 and a cement content of $405 \mathrm{~kg} / \mathrm{m}^{3}$. Table 3 presents concrete compositions and properties of fresh concretes. The proportions of aggregate were the same for both mixes, but the gravel/sand $(\mathrm{G} / \mathrm{S})$ ratio value may be considered a little low for GC according to Dreux composition [10]. It was imperative to calculate the amount of water to be added to the mix, so as not to modify the effective W/C ratio and maintain the concrete workability. Due to its absorption capacity, aggregate must be wet before its employment in making concrete. If the coarse aggregate is not humid, it would absorb water from the paste thus losing both its workability in the fresh concrete, and also the control of the effective $\mathrm{W} / \mathrm{C}$ ratio in the paste. The coarse aggregates were wet the day before casting and they were covered with a plastic sheet in order to maintain their high humidity. The levels of humidity were $80 \% \pm 10 \%$ of the total absorption capacity.

Table 3. Mix proportions and properties of fresh concretes.

\begin{tabular}{|c|c|c|c|c|}
\hline Nomenclature & SR & GC & LC & SC \\
\hline Type of aggregate & $\begin{array}{c}\text { Rolled } \\
\text { siliceous gravel }\end{array}$ & $\begin{array}{c}\text { Crushed } \\
\text { granite gravel }\end{array}$ & $\begin{array}{c}\text { Crushed } \\
\text { limestone }\end{array}$ & $\begin{array}{c}\text { Crushed } \\
\text { siliceous gravel }\end{array}$ \\
\hline Cement CEMI 52,5R & 405 & 405 & 405 & 405 \\
\hline Densified Silica Fume & 45 & 45 & 45 & 45 \\
\hline Water/Binder & 0,35 & 0,35 & 0,35 & 0,35 \\
\hline Superplasticizer/Binder (\%) & 2 & 2 & 2 & 2 \\
\hline Sand & 755 & 755 & 1133 & 944 \\
\hline Coarse aggregate & 1133 & 1133 & 2467 & 2462 \\
\hline Density of fresh concrete & 2497 & 2464 & 18 & 20 \\
\hline Slump (cm) & 17 & 18 & & \\
\hline
\end{tabular}

The following mechanical tests have been performed on three samples for each test.

-Compressive strength was measured with a $3000 \mathrm{KN}$ hydraulic press with a loading rate of 0.5 $\mathrm{MPa} / \mathrm{s}$. 
-The E-modulus corresponds to the secant modulus at 30\% of the rupture stress. The E-modulus is assessed with an "extensometric" system with two induction sensors which measure axial strains between two rings (12 cm of distance between the two rings). The extensometric system is shown in Figure 2 (a).

-Shrinkage measurements started at $24 \mathrm{~h}$. The axial strains can be measured with two steel contacts fixed to the ends of the specimen with a mechanical micrometric sensor (Figure 2 (b)).

-The creep strains can be measured with LVDT sensor placed in a reservation on the axis of the concrete cylinder (Figure 2 (c)).

The compressive strength and modulus of elasticity tests were performed at 3 and 28 days. Two storing conditions have been studied: in desiccation $50 \% \mathrm{RH}$ and $20^{\circ} \mathrm{C}$, and in self-desiccation, i.e. without hygrometric exchanges at $20^{\circ} \mathrm{C}$. The samples for the autogenous tests were sealed with double layers of adhesive aluminium foils. For the creep and shrinkage tests, the RILEM recommendations [11] has been respected. Creep loads are applied after 3 days of hardening. Loading levels represent $40 \%$ of the compressive strength measured at loading age.

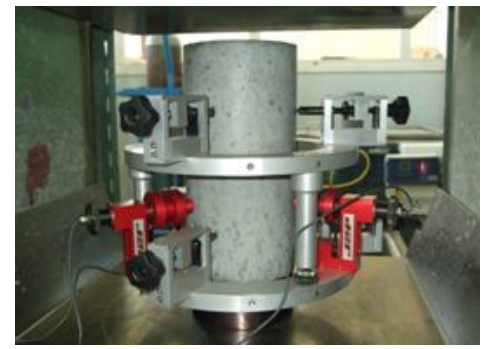

(a)

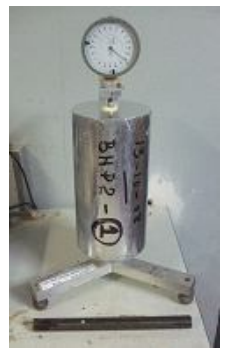

(b)

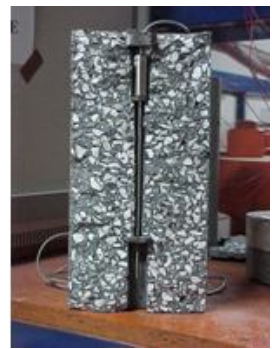

(c)

Fig. 2. Extensometric system to measure axial strain (a), shrinkage (b) and creep (c) test setup realized on cylindrical specimens $(118 \times 236 \mathrm{~mm})$.

\section{Experimental results and discussion}

\subsection{Mechanical properties of hardened concrete}

The modulus of elasticity of concrete is a parameter necessary in structural analysis for the determination of the strain distributions and displacements, especially when the design of the structure is based on elasticity considerations. This property is conventionally measured using standardized tests based on small specimens subjected to uniaxial compressive loading.

Table 4 shows the evolutions of compressive strength and modulus of elasticity at 3 days (age of beginning of creep test) and 28 days. Although the mix was similar for the four HPC, the values at 28 days vary respectively between 72.1 and $94.7 \mathrm{MPa}$ for compressive strength and between 38.3 and $47.7 \mathrm{GPa}$ the modulus of elasticity, underlining the influence of the nature of the gravel.

Table 4. Mechanical properties of hardened concrete prepared with the coarse aggregates selected.

\begin{tabular}{|l|c|c|c|c|c|}
\hline & Age (days) & SR & SC & GC & LC \\
\hline Compressive & 3 & 54.5 & 45.9 & 52.9 & 66.7 \\
\cline { 2 - 6 } strength (MPa) & 28 & 82.2 & 72.1 & 76.9 & 94.7 \\
\hline $\begin{array}{l}\text { Modulus of } \\
\text { elasticity (GPa) }\end{array}$ & 3 & 30.8 & 32.7 & 35.9 & 36.1 \\
\cline { 2 - 6 } & 28 & 38.3 & 39.8 & 42.5 & 47.7 \\
\hline
\end{tabular}

Eurocode 2 correlates directly the modulus of elasticity to the compressive strength. In order to verify the accuracy of its formula, Figure 3 presents a comparison between the increasing evolution of modulus of versus the compressive strength calculated from this model code and the experimental 
results obtained in this study and data collated from the available literature $[1,2,12,13,14,15,16]$. The mineralogical nature of aggregate is also indicated.

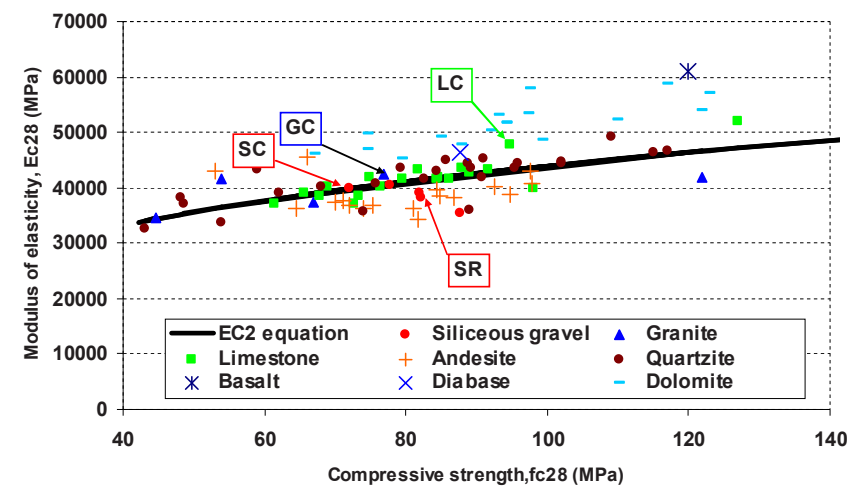

Fig. 3. Influence of compressive strength of concrete and coarse aggregate type on the modulus of elasticity of concrete.

Eurocode 2 globally proposes a good prediction of the increase of the modulus of elasticity from the only compressive strength parameter. However, some results tend to prove that this parameter is not sufficient and that the effect of the type of coarse aggregate is pronounced. For example, the modulus of elasticity of concretes with andesite aggregate is higher than those of the granite concrete whereas their compressive strength is lower: between 50 and $60 \mathrm{MPa}$ for andesite concretes and over $120 \mathrm{MPa}$ for the granite concrete. The results of concretes with dolomite aggregate, which is characterized by a modulus of elasticity generally $30-50 \%$ higher than those of other materials, are always above the model code curve.

The experimental values seem to be well correlated by the model. However, it underestimates the value of the concrete with limestone aggregate (LC) which corresponds to the greatest aggregate modulus of elasticity. Thus, it appears that the modulus of elasticity of concrete is a function of the stiffness of coarse aggregate and not only of the compressive strength. It may also be dependant on the volume fraction of aggregate. Other factors could have an influence as the nature of the interfacial zone between aggregates and paste [4] linked to the nature of aggregate. Additionally, the adding of silica fume into mixtures increases the densification and the stiffness of concretes.

\subsection{Effect of aggregate quality on the shrinkage}

Figure 4 (a) presents the evolutions of autogenous and total shrinkages of the four HPC and Eurocode 2 predictions. The HPC with rolled siliceous aggregate develops the highest strains in autogenous and desiccation conditions, maybe due to the shape of the aggregate compared to the other gravels used. The shrinkage of the others HPC are similar in autogenous condition but quite different in desiccation one. Eurocode 2 underestimates the experimental results and do not predict the differences observed experimentally in desiccation condition since its formula depends only on the compressive strength which are rather comparable for the four HPC.

The experimental values of autogenous and total shrinkage of concrete after 180 days made with different types of aggregates from the literature $[1,2,15,17,18]$ and our results have been presented in Figure 4 (b). The data are expressed versus the compressive strength. This parameter corresponds to the main parameter of Eurocode 2 shrinkage model. In desiccation condition, the sample geometry and the relative humidity are also taken into account. However, their variations following the experimental conditions of the different researches can be considered as negligible. 


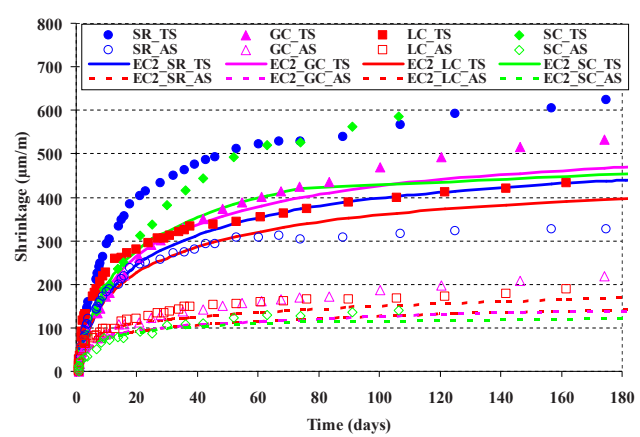

(a)

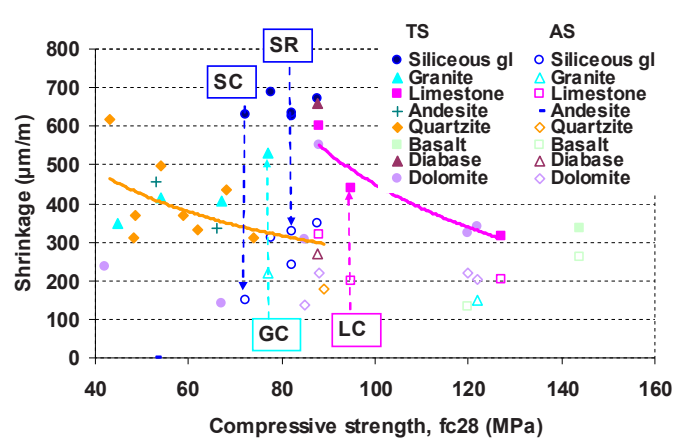

(b)

Fig. 4. Influence of compressive strength and aggregate type on Autogenous (AS) and Total (TS) shrinkage at 180 days of concrete

From this figure, autogenous and total shrinkage can not only be linked to compressive strength. For a same concrete resistance, free delayed strains after 180 days present a large scatter for concretes with various nature of aggregate. And an equivalent shrinkage can be found for concrete resistance from $40 \mathrm{MPa}$ up to $140 \mathrm{MPa}$.

If the analysis is focused on the total shrinkage results of various concrete incorporating the same nature of aggregate, in particular for quartzite and limestone (trend curves represented in Figure 4 (b)), the relationship between shrinkage and compressive strength seem to become clearer. This tends to prove that considering both the type of aggregate and the resistance could improve the prediction of shrinkage. In the specific case of our HPC, the highest shrinkage strains are obtained for the concretes with siliceous aggregates which the modulus of elasticity is the weakest. This observation is in accordance with previous work of Alexander [4] which concluded that the stiffness of aggregate restrains the movement of the cement paste. Other parameters linked to aggregates can be influent. Although, unfortunately, these informations are not always available in the literature, their volume fraction [4] and their physical properties could also play a role. Thus, the aggregates which have moderate initial moisture content, depending on the condition of storage, absorb a certain amount of free water, and lower the initial W/C in the interfacial transition zone ITZ at early hydration. Newly formed hydrates gradually fill the region and strengthen the interfacial bond between the aggregates and cement [19]. These phenomena could finally generate various shrinkage behaviours.

\subsection{Effect of aggregate quality on the creep}

Creep strain was calculated by deducting from total strain under loading; the initial elastic strain (which occurred immediately after application of the load) and the average shrinkage strain of the unloaded specimens group. The creep coefficients were determined by dividing the creep strains by the measured elastic strains. The variations of basic (autogenous condition) and total (desiccation condition) creep coefficient for the four HPC have been presented on Figure 5 (a). The creep coefficient in autogenous conditions is close for all HPC. Eurocode 2 proposes a good correlation of the kinetics but underestimates the intensity of this parameter.

In desiccation condition, the experimental values present an important scatter. The weakest creep coefficient is obtained for the HPC with the rolled siliceous. As for the autogenous shrinkage, the shape of the gravel seems to have an effect, although that it is not in the same way. The evolutions for the three other HPC are similar until 50 days but, after, are divergent. Eurocode 2 does not predict with a correct accuracy the total creep coefficient variations following the nature of aggregate since, as for shrinkage formulas, it is calculated from the compressive strength and the desiccation conditions parameters (sample geometry and relative humidity) which are the comparable in this study. 


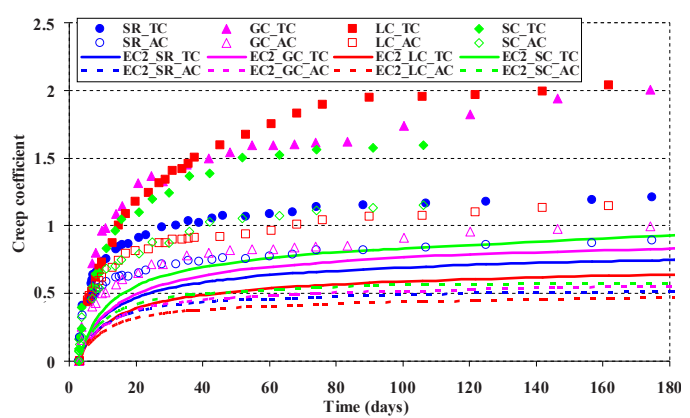

(a)

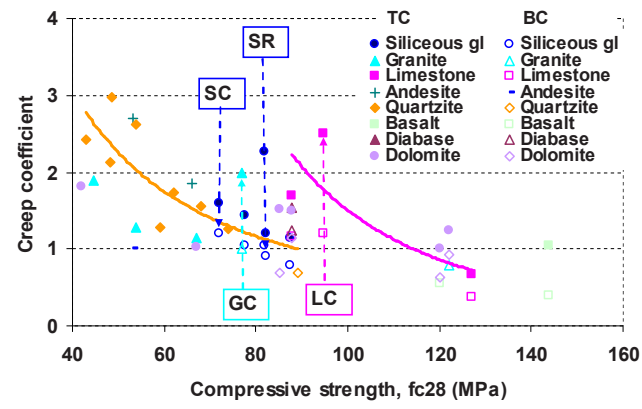

(b)

Fig. 5. Creep coefficient at 180 days in autogenous condition (Basic Creep BC) and in desiccation condition (Total Creep TC) of concrete with different types of coarse aggregates.

Figure 5 (b) presents the creep coefficients after 180 days of testing in autogenous and desiccation conditions from our experimental study and from the literature versus the concrete compressive strength $[1,2,15,17,18]$. The analysis is analogous to the Figure 5 (a) about the shrinkage. The figure shows a great scatter of values of creep coefficient for a same resistance. However, if the evolution of this parameter is observed for concretes incorporating a same nature of aggregate (quartzite or limestone), a trend seems to appear with a logical reduction of the creep coefficient with the raise of the compressive strength. Concerning our experimental results, on the contrary of shrinkage behaviour, the weakest creep coefficient is not observed for the HPC with limestone aggregate which have the most important stiffness. So, if the nature of aggregate seems influent, their different creep behaviour can not only be explained by a variation of their stiffness.

The creep phenomenon is more complex than the shrinkage one. The creep mechanism can be explained by the viscous slippage between C-S-H sheets [20]. The differential deformability of the paste and the aggregate (which do not creep) under loading reveals the importance of the quality of the interfacial transitional zone (ITZ). So, the variability of creep results could come from the forces of adhesion of the coarse aggregate with the paste. On one hand, there are physical forces whose magnitude depends on the topography of aggregate grain surface and on the grain shape, and on the other hand, there are the forces of chemical bond created by the chemical activity of the aggregate towards the cement paste [21]. From the analysis, the concrete age at the time of creep loading associated to the hydration of cement paste in the ITZ would also have an effect on creep kinetic.

These conclusions and assumptions have to be moderated since the results presented here correspond to 180 days of testing and the kinetics are not negligible. Values after one year will be more significant.

\section{Conclusions}

This study investigated the effect of the nature of aggregate on instantaneous (modulus of elasticity) and delayed (shrinkage and creep) mechanical behaviour of four HPC with the same mixture but different type of gravel. From the experimental results, literature data and comparison with Eurocode 2 predictions, the following conclusions have been drawn:

- Eurocode 2 proposes a good prediction of the modulus of elasticity of the concretes using the single parameter of the compressive strength. However, from the observation of singular results, in particular for the HPC with limestone gravel, its accuracy could be improved by taking into account the stiffness of aggregate and probably its volume fraction in the mixture.

- The shrinkage results are different following the nature and also the shape of the gravels. Eurocode 2 underestimates the intensity of experimental shrinkage. Whereas this model mainly links the shrinkage strain to the compressive strength, the experimental and the literature results present an important scatter for equivalent concrete resistance. For concretes incorporating the 
same nature of aggregate, a correlation between compressive strength and total shrinkage seems to appear, traducing the influence of the nature of aggregate on shrinkage and thus the limit of Eurocode 2 model. On the basis of the HPC results, the shrinkage is weaker when the stiffness of the aggregate is high (limestone). Other parameter as the volume fraction, the shape and physical properties of the aggregate could be also influent and have to be studied.

-The analysis of creep results shows some differences at long term in desiccation condition (total creep) between the four HPC. The lowest creep coefficient is obtained for the HPC with rolled siliceous gravel. As for shrinkage study, the experimental and literature creep coefficients presented versus the concrete compressive strength, main parameter of Eurocode 2 model for creep, reveal a great variability. If the analysis is focused on concrete incorporating the same nature of aggregate, creep coefficient of concrete clearly tends to decrease when concrete resistance is enhanced. On the contrary to shrinkage, the influence of the gravel stiffness has not been observed. This could be explained by the more complex mechanism of creep. The creep strain could be more correlated to the differential deformability of cement paste and the aggregate and thus to the resistance of the ITZ between the two phases, dependant on the nature of the coarse aggregate.

\section{References}

1. W. Baalbaki, B. Benmokrane, O. Chaallal, and P. Aitcin, "Influence of Coarse Aggregate on Elastic Properties of High-Performance Concrete”, ACI Materials Journal, vol. 88, 1991.

2. J.F. Cubaynes and G. Pons, "Influence of the type of coarse aggregates on shrinkage and creep of high strength concrete", 4th Symposium on Utilization of High-Strength /HPC, Paris: 1996.

3. X. Feng and S. Yu, "Effects of Reinforcement Shape on the Effective Moduli of Composites (I)", Journal of Tsinghua University, vol. 41, 2001.

4. M.G. Alexander, "Aggregates and the Deformation Properties of Concrete", ACI Materials Journal, vol. 93, 1996.

5. A. Mokhtarzadeh and C. French, "Time-Dependent Properties of High-Strength Concrete with Consideration for Precast Applications", ACI Materials Journal, vol. 97, 2000.

6. W.A. Tasong, C.J. Lynsdale, and J.C. Cripps, "Aggregate-cement paste interface: Part I. Influence of aggregate geochemistry", Cement and Concrete Research, vol. 29, 1999.

7. J. Maso, Interfacial transition zone in cement, London: 1996.

8. Eurocode 2, EN1992-2, Design of concrete structures. Concrete bridges, 2006.

9. Norme Française XP P 18-545, “Granulats. Eléments de définition, conformité et codification”, 2008.

10. G. DREUX et J. FESTA, Nouveau guide du béton, 1995.

11. Standardized Test Methods for Creep and Shrinkage, "Measurement of time-dependent strains of concrete", Materials and Structures, vol. 31, 1998.

12. D. Mostofinejad and M. Nozhati, "Prediction of the Modulus of Elasticity of High Strength Concrete", Iranian Journal of Science \& Technology, vol. 29, 2005.

13. P. Munoz, "Rhéologie des bétons durcis : Approche couplée de la modélisation des retraits et fluages de bétons a hautes et très hautes performances”, Thèse de doctorat, INSA, Toulouse, France, 2000.

14. Y. Yssorche, "Microfissuration et durabilité des bétons à hautes performances", Thèse de doctorat, INSA, Toulouse, France, 1995.

15. I. Schrage and R. Springenschimid, "Creep and shrinkage data of high-strength concrete," 4th Symposium on Utilization of High-Strength /HPC, Paris: 1996.

16. M.S. Meddah, S. Zitouni, and S. Belâabes, "Effect of content and particle size distribution of coarse aggregate on the compressive strength of concrete", Construction and Building Materials, vol. 24, 2010.

17. P. Aitcin, "From gigaPascals to nanometers", Potosi, Missouri: 1988.

18. B. Persson, "Influence of maturity on creep of high performance concrete with sealed curing", Materials and Structures, vol. 32, 1999.

19. C. Poon, Z. Shui, and L. Lam, "Effect of microstructure of ITZ on compressive strength of concrete prepared with recycled aggregates", Construction and Building Materials, vol. 18, 2004.

20. P. Acker and F. Ulm, "Creep and shrinkage of concrete: physical origins and practical measurements", Nuclear Engineering and Design, vol. 203, 2001.

21. G. Prokopski and J. Halbiniak, "Interfacial transition zone in cementitious materials", Cement and Concrete Research, vol. 30, 2000. 